6 Dawber TR. The Framingham study: the epidemiology of atherosclerotic disease. Cambridge, Massachusetts: Harvard University Press, 1980.

7 Brunzell JD, Miller NE. Atherosclerosis in inherited and acquired disorders of plasma lipoprotein metabolism. In: Miller NE, Lewis B, eds. Lipoproteins, atherosclerosis and coronary heart disease. Amsterdam: Elsevier North Holland Biomedical Press, 1981:73-88.

8 Kennedy AL, Lappin TRJ, Lavery TD, Hadden DR, Weaver JA, Montgomery DAD. Relation of high-density lipoprotein cholesterol concentration to type of diabetes and its control.
ond of high-density lipoprotein

9 Nikkila EA, Hormila P. Serum lipids and lipoproteins in insulin-treated diabetics. Demonstration of increased high density lipoprotein concentrations. Diabetes 1978;27:1078-85.

10 Mattock MB, Fuller JH, Maude PS, Keen H. Lipoprotein and plasma cholesterol esterification in normal and diabetic subjects. Atherosclerosis 1979;34:439-49.

11 Durrington PN. Serum high density lipoprotein cholesterol in diabetes mellitus: an analysis of factors which influence its concentration. Clin Chim Acta 1980;104:11-23.

12 Sosenko JM, Breslow JL, Mieltenen DS, Gabbay KH. Hyperglycemia and plasma lipid levels: a prospective study of young insulin dependent diabetic patients. N Engl I Med 1980;302:650-4

13 Winocour PH, Durrington PN, Ishola M, Anderson DC. Lipoprotein abnormalities in insulindependent diabetes mellitus. Lancet 1986;:1176-8.

14 Schonfeld G, Birge C, Miller JP, Kellser G, Santiago J. Apolipoprotein B levels and altered lipoprotein composition in diabetes. Diabetes 1974;23:927-34.

15 Nikkila EA. High density lipoprotein in diabetes. Diabetes 1981;30:82-7.
16 Durrington PN. Serum high density lipoprotein cholesterol subfractions in type 1 (insulinDurrington PN. Serum high density lipoprotein cholesterol
dependent) diabetes mellitus. Clin Chim Acta 1982;120:21-8.

17 Mattock MB, Salter AM, Fuller JH, et al. High density lipoprotein subfractions in insulindependent diabetic and normal subjects. Atherosclerosis 1982;45:67-9.

18 Cruickshank KJ, Orchard TJ, Becker DJ. The cardiovascular risk profile of adolescents with insulin dependent diabetes mellitus. Diabetes Care 1985;8:118-24.

19 Hulley SB, Rosenmann BH, Bawol RD, Brand JJ. The association between triglyceride and coronary heart disease. $N$ Engl f Med 1980;302:1383-9.

20 West KM, Ahuja MMS, Bennett PH, et al. The role of circulating glucose and triglyceride concentrations and their interaction with other "risk factors" as determinants of arterial disease in nine diabetic population samples from the WHO multinational study. Diabetes Care in nine diabetic

21 Janka HV. Five year incidence of major macrovascular complications in diabetes mellitus. In: Janka HV, Mehnert H, Standl E, eds. Macrooascular disease in diabetes mellitus, pathogenesis and Janka HV, Mehnert H, Standl E, eds. Macrovascular disease in

22 Havel RJ, Goldstein JL, Brown MS. Lipoproteins and lipid transport. In: Bondy PK, Rosenberg LE, eds. Metabolic control and disease. Philadelphia: W B Saunders, 1980:393-494.

23 Andersen AR, Christiansen JS, Andersen JK, Kreiner S, Deckert T. Diabetic nephropathy in type 1 (insulin dependent) diabetes mellitus: an epidemiological study. Diabetologia 1983;25: 496-501

24 Viberti GC, Hill RD, Jarrett RJ, Argyropoulus A, Mahmud U, Keen H. Microalbuminuria as a predictor of clinical nephropathy in insulin-dependent diabetes mellitus. Lancet 1982;i:1430-2.

25 Borch-Johnsen K, Andersen PK, Deckert T. The effect of proteinuria on relative mortality in type 1 (insulin-dependent diabetes mellitus). Diabetologia 1985;28:590-6.

26 Short CD, Durrington PN, Mallick NP, Hunt LP, Tetlow L, Ishola M. Serum and urinary high density lipoproteins in glomerular disease with proteinuria. Kidney Int 1986;29:1224-8.

27 Mallick NP, Short CD. The nephrotic syndrome and ischaemic heart disease. Nephron $1981 ; 27: 54-7$.

28 Havel RJ, Eder HA, Bragdon JH. The distribution and chemical composition of ultracentrifugally separated lipoproteins in normal serum. F Clin Invest 1955;34:1345-53.

29 Burstein M, Scholnick HR, Morfin R. Rapid method for the isolation of lipoproteins from human serum by precipitation with polyanions. $\mathcal{F}$ Lipid Res 1970;11:583-95
30 Friedewald WT, Levy R, Fredrickson DS. Estimations of serum low density lipoprotein cholesterol without use of preparative ultracentrifuge. Clin Chem 1972;18:499-502.

31 Durrington PN, Whicher JT, Warren C, Bolton CH, Hartog M. A comparison of methods for the immuoassay of serum apolipoprotein B in man. Clin Chim Acta 1972;71:95-108.

32 Fielding BA, Price DA, Houlton CA. Enzyme immunoassay for urinary albumin. Clin Chem 1983;29:355-7.

33 Wiseman M, Viberti G, Macintosh D, Jarrett RJ, Keen H. Glycaemia, arterial pressure and microalbuminuria in type 1 (insulin-dependent) diabetes mellitus. Diabetologia 1984;26:401-5.

34 Mathiesen ER, Oxenboll B, Johansen K, Svendsen PAa, Deckert T. Incipient nephropathy in type 1 (insulin-dependent) diabetics. Diabetologia 1984;26:406-10.

35 Hasslacher $\mathrm{Ch}$, Stech W, Wahl P, Ritz E. Blood pressure and metabolic control as risk factors for nephropathy in type 1 (insulin-dependent) diabetes. Diabetologia 1985;26:6-11.

36 Feldt-Rasmussen B. Increased transcapillary escape rate of albumin in type 1 (insulin-dependent) diabetic patients with microalbuminuria. Diabetologia 1986;29:282-6.

37 Ross R. The pathogenesis of atherosclerosis: an update. N Engl f Med 1986;314:418-22.

38 Skovborg F. Blood viscosity in normal and diabetic subjects. A clinical-hemorrheological study. Copenhagen: Fad's Forlag, 1974. (PhD thesis.)

39 Valdorf-Hansen W. Coagulability in diabetics. Acta Med Scand 1967;476(suppl);147-57.

40 Vannini $P$, Giavarella A, Flammini $M$, et al. Lipid abnormalities in insulin-dependent diabetic patients with albuminuria. Diabetes Care 1984;7:151-4.

41 Eckel RH, McLean E, Albers JJ, Cheung MC, Bierman EL. Plasma lipids and microangiopathy in insulin-dependent diabetes mellitus. Diabetes Care 1981;4:447-53.

42 Durrington PN. A comparison of three methods of measuring serum high density lipoprotein cholesterol in diabetics and non-diabetics. Ann Clin Biochem 1980;17:199-204.

43 Kostner GM. Lipoprotein Lp(a) in man: structure, metabolism and myocardial infarction risk. In: Crepaldi G, LeFebre PJ, Galton DJD, eds. Diabetes, obesity and hyperlipidaemia II. London: Academic Press, 1983:9-14.

44 Kverneland A, Feldt-Rasmussen B, Vidal P, et al. Evidence of changes in renal charge selectivity in patients with type 1 (insulin-dependent) diabetes mellitus. Diabetologia 1986;29:634-9.

45 Witztum JL, Fisher M, Metro T, Steinbrecher V, Glam RI. Non-enzymatic glycosylation of high density lipoprotein accelerates its catabolism in guinea pigs. Diabetes 1982;31:1029-34.

46 Glass CK, Pittman RC, Keller GA, Steinberg D. Tissue sites of degradation of apoprotein A-I in the rat. $\mathcal{F}$ Biol Chem 1983;258:7161-7.

47 Segal P, Gidez LI, Vega G, Edelstein D, Eder HA, Roheim PS. Apoproteins of high density lipoproteins in the urine of normal subjects. $\mathcal{F}$ Lipid Res 1979;20:784-8.

48 Shore VG, Forte T, Licht H, Lewis SB. Serum and urinary lipoproteins in the human nephrotic syndrome: evidence for renal catabolism of lipoproteins. Metabolism 1982;31:258-68.

49 Nikkila EA. Triglyceride metabolism in diabetes mellitus. Prog Biochem Pharmacol 1973;8 271-99.

50 Parving HH, Andersen AR, Smidt UM, Oxenboll B, Edsberg G, Christiansen JS. Diabetic nephropathy and arterial hypertension. Diabetologia 1983;24:10-2.

51 Telmer S, Christiansen JS, Andersen AR, Nerup J, Deckert T. Smoking habits and prevalence of clinical diabetic microangiopathy in insulin-dependent diabetics. Acta Med Scand 1984;215: 63-8.

52 Nielsen MM, Hiøllund E. Smoking and diabetic microangiopathy. Lancet 1978;ii:533-4.

53 Mulhauser I, Sawicki P, Berger M. Cigarette smoking as a risk factor for macroproteinuria and proliferative retinopathy in type 1 (insulin-dependent) diabetes. Diabetologia 1986;29:500-2.

54 Dornan TL, Carter RD, Bron AJ, Turner RC, Mann JI. Low density lipoprotein cholesterol: an association with the severity of diabetic retinopathy. Diabetologia 1982;22:167-70.

55 Moorhead JF, Chan MK, El-Nahas M, Varghese Z. Lipid nephrotoxicity in chronic progressive glomerular and tubulo-interstitial disease. Lancet 1982;ii:1309-11.

(Accepted 27 March 1987)

\title{
Proteinuria: value as predictor of cardiovascular mortality in insulin dependent diabetes mellitus
}

\author{
KNUT BORCH-JOHNSEN, SVEND KREINER
}

\begin{abstract}
The relation between diabetic microangiopathy and macroangiopathy was studied by analysing the relative mortality from cardiovascular disease in patients with insulin dependent diabetes mellitus with and without persistent proteinuria. The study group comprised 2890 diabetics diagnosed between 1933 and 1972 before the age of 31 , and the study was conducted by using the linear logistic discrete failure time model. In patients with proteinuria the relative mortality from cardiovascular disease was 37 times that in the general population; in patients without
\end{abstract}

Steno Memorial Hospital, DK-2820 Gentofte, Denmark

KNUT BORCH-JOHNSEN, MD, research fellow

Department of Data Processing, Copenhagen County Hospital, DK-2730 Herlev, Denmark

SVEND KREINER, MSC, statistical consultant

Correspondence to: Dr Borch-Johnsen. proteinuria it was $4 \cdot 2$ times that in the general population. In both groups women had a relative mortality twice to 2.6 times that of men. In neither group was relative mortality correlated with duration of diabetes, suggesting that the association between diabetes and cardiovascular disease may be conferred by factors other than hyperglycaemia and hyperinsulinaemia.

The high relative mortality from cardiovascular disease in diabetics with proteinuria indicates a strong association between diabetic microangiopathy and macroangiopathy, suggesting a common (pathogenetic?) mechanism for these two late diabetic complications.

\section{Introduction}

Insulin dependent diabetes is characterised by a high relative mortality, ${ }^{1}$ which recent studies have shown is confined almost entirely to patients developing persistent proteinuria. ${ }^{2}$ Furthermore, mortality from cardiovascular disease also tends to be higher in patients with proteinuria than in those without. ${ }^{2}$ Previous studies 
on non-insulin-dependent diabetics have shown diabetes mellitus to be associated with increased cardiovascular morbidity and mortality ${ }^{3}$ but the underlying pathogenetic mechanism remains unknown. ${ }^{5}$ The few similar studies on insulin dependent diabetics also suggest an excess of cardiovascular morbidity and mortality in these patients. ${ }^{2}{ }^{6}$ Recent Danish and British studies on non-insulindependent diabetics have shown that patients with abnormally high urinary albumin excretion rates but without clinical nephropathy have an excess cardiovascular mortality rate. ${ }^{78} \mathrm{We}$ therefore hypothesised that persistent proteinuria is a marker of a generalised severe (malignant) vasculopathy including microangiopathy as well as macroangiopathy, suggesting a common (pathogenetic?) mechanism for the two types of diabetic angiopathy. The aim of the present study was to analyse the relative mortality from cardiovascular disease in a dynamic cohort of insulin dependent diabetic patients with and without persistent proteinuria.

\section{Present study}

\section{SUBJECTS}

The study group comprised all 2890 insulin dependent diabetics admitted to the Steno Memorial Hospital (a specialised diabetes care unit) whose disease was diagnosed before the age of 31 between 1933 and 1972. The study population and the incidence of proteinuria are detailed elsewhere. ${ }^{9}$ Estimated on the basis of a Danish incidence study ${ }^{10}$ the population represented between $25 \%$ and $35 \%$ of all insulin dependent diabetics diagnosed between 1933 and 1972 . The distribution of sex and age at onset of diabetes showed no difference between our population and the incidence study. All patients were admitted to the Steno Memorial Hospital between 1933 and 1982 for specialist advice on diabetes care. Two thirds were followed up regularly at the hospital and the remaining patients by their general practitioners backed by local departments of internal medicine. Treatment at the hospital is free and patients are referred by their general practitioners or the departments of internal medicine. The Steno Memorial Hospital is one of the two main Danish centres for treatment of diabetes.

All patients were followed up from admission to the hospital until death, emigration, or 1 January 1984 by tracing their personal identification numbers at the National Central Register. A total of 716 of the patients had died. In all these cases a copy of the death certificate, the necropsy report (if any), and the records from the last admission were obtained to verify the cause of death. Data on proteinuria were obtained from the hospital records at the Steno Memorial Hospital or the medical or paediatric departments and general practices where the patients had been followed up. Persistent proteinuria was defined as urinary protein excretion exceeding $0.5 \mathrm{~g}$ in 24 hours in four consecutive urine samples from patients without urinary tract infection, congestive heart failure, or pregnancy. The screening procedure for proteinuria was Heller's test until 1965, and thereafter reagent strips (predominantly Albustix) were used. ${ }^{11}{ }^{12}$ If proteinuria was detected quantitative determination was carried out by the Esbach method. ${ }^{11}$ All patients were screened routinely at each outpatient clinic visit and while in hospital.

Of the 2890 patients who could be traced, data on proteinuria were unobtainable in 232, nine had died before 1943 , and seven had developed non-diabetic proteinuria before admission and 49 non-diabetic proteinuria after admission to the hospital. Thus 248 patients were excluded from the analysis and 49 excluded from the onset of non-diabetic proteinuria. A total of 2642 patients were included in the analysis of relative cardiovascular mortality, of whom 197 had proteinuria on admission and 525 developed proteinuria during the study period (see fig 1). In 110 patients the exact date at onset of proteinuria was unknown; nevertheless, having recorded the last time the patient had been seen without proteinuria and the first time with proteinuria, we estimated the most probable time of onset, as described. ${ }^{2}$

For analysis of the cardiovascular relative mortality the cause of death of the insulin dependent diabetics was taken from the death certificates. For comparison the age specific, sex specific, and calendar year specific mortality rates for cardiovascular disease were obtained from the Danish Institute of Clinical Epidemiology. As the central registration of death certificates in Denmark began in 1943, this study covers the relative mortality from cardiovascular disease for 1943-83 only. The coding procedure for death certification in Denmark changed during the study period. Not until 1951 did Denmark adopt the international coding system for death certification (World Health Organisation's International Classification of Diseases). Before then Scandinavian countries had used their own standardised nomenclature. Thus the following codes were used to define cardiovascular disease: 1943 to 1950 (Scandinavian nomenclature of $1926^{13}$ ) codes 250,300 , and 400 to $430 ; 1951$ to 1968 (ICD (7th revision)), codes 330 to 334 and 400 to $468 ; 1969$ to 1983 (ICD (8th revision)), codes 390 to 458 . The definition

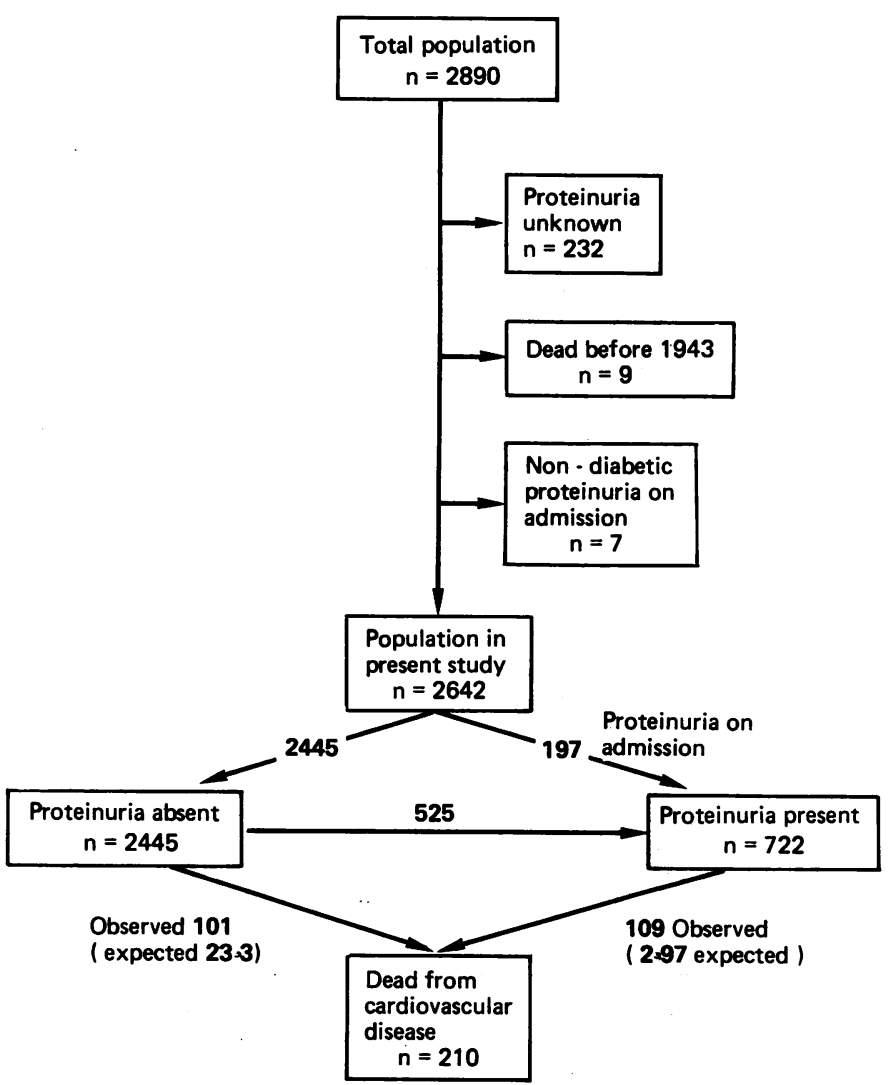

FIG 1-Flow chart of patients studied.

TABLE I-Clinical data on patients developing persistent proteinuria and patients not developing proteinuria

\begin{tabular}{lcccc}
\hline & $\begin{array}{c}\text { No } \\
\text { studied }\end{array}$ & $\begin{array}{c}\text { No(\%) } \\
\text { male }\end{array}$ & $\begin{array}{c}\text { Median age at } \\
\text { diagnosis (years) } \\
\text { (range) }\end{array}$ & $\begin{array}{c}\text { Median calendar year } \\
\text { of diagnosis (range) }\end{array}$ \\
\hline $\begin{array}{l}\text { Proteinuric group } \\
\begin{array}{l}\text { Non-proteinuric } \\
\text { group }\end{array}\end{array}$ & 722 & $476(66)$ & $14(1-30)$ & $1949(1933-72)$ \\
& 1871 & $992(53)$ & $\begin{array}{c}15(1-30) \\
\mathrm{p}<0.01 \dagger\end{array}$ & $\begin{array}{c}1959(1933-72) \\
\mathrm{p}<0.0001 \dagger\end{array}$ \\
\hline
\end{tabular}

${ }^{\star} \chi^{2}$ Test. †Mann-Whitney test.

TABLE II-Predictors of increased cardiovascular relative mortality in patients with proteinuria

\begin{tabular}{|c|c|c|c|c|}
\hline & $-2 \log Q$ & $\begin{array}{c}\text { Degrees } \\
\text { of } \\
\text { freedom }\end{array}$ & $\mathbf{p}$ & $\begin{array}{l}\text { Odds } \\
\text { ratio }\end{array}$ \\
\hline \multicolumn{5}{|c|}{ Significant predictors of cardiovascular mortality } \\
\hline \multicolumn{5}{|l|}{ Age (years): } \\
\hline$\leqslant 25$ & $23 \cdot 15$ & 3 & 0.00004 & $1 \cdot 0$ \\
\hline $26-35$ & & & & $1 \cdot 5$ \\
\hline $36-45$ & & & & $1 \cdot 4$ \\
\hline$\geqslant 46$ & & & & $0 \cdot 3$ \\
\hline \multicolumn{5}{|l|}{ Year of diagnosis: } \\
\hline $1933-40$ & 9.05 & 3 & 0.03 & $1 \cdot 0$ \\
\hline $1941-45$ & & & & $0 \cdot 6$ \\
\hline $1946-55$ & & & & 0.5 \\
\hline $1956-65$ & & & & 0.6 \\
\hline \multicolumn{5}{|l|}{ Calendar year during follow up: } \\
\hline $1943-55$ & $11 \cdot 78$ & 4 & 0.02 & $1 \cdot 0$ \\
\hline $1956-65$ & & & & $1 \cdot 2$ \\
\hline $1966-70$ & & & & 3.9 \\
\hline $1971-75$ & & & & $3 \cdot 3$ \\
\hline $1976-83$ & & & & $2 \cdot 8$ \\
\hline \multicolumn{5}{|l|}{ Age at onset of proteinuria (years): } \\
\hline$\leqslant 20$ & $12 \cdot 10$ & 2 & 0.003 & $1 \cdot 0$ \\
\hline $21-30$ & & & & $0 \cdot 8$ \\
\hline$\geqslant 31$ & & & & $0 \cdot 4$ \\
\hline \multicolumn{5}{|c|}{ Variables with insignificant effect } \\
\hline Age at diagnosis & $6 \cdot 61$ & 5 & $0 \cdot 25$ & \\
\hline Duration of proteinuria & 0.01 & 2 & 0.99 & \\
\hline Duration of diabetes on admission & $3 \cdot 29$ & 2 & $0 \cdot 19$ & \\
\hline Year of onset of proteinuria & $4 \cdot 40$ & 3 & 0.22 & \\
\hline Duration of diabetes at onset of proteinuria & 0.01 & 1 & 0.92 & \\
\hline
\end{tabular}


included Morbi Organorum Cirkulationis-that is, ischaemic heart disease, cardiac valvular disease, unspecified cardiac disease, cerebrovascular disease, peripheral vascular disease, thromboembolic events, and hypertension.

\section{STATISTICAL MODEL AND METHODS}

Analysis of the relative mortality from cardiovascular disease was performed within the framework of a linear logistic discrete failure time model ${ }^{14}{ }^{15}$ where time (duration of diabetes) was measured in years. Statistical analysis was by likelihood ratio test statistics $(-2 \log Q)$. For each subject the sex specific, age specific, and calendar year specific cardiovascular disease death intensities were included as an additional part of the logistic parameter. The state of the patient (dead, alive, or censored due to loss to follow up or termination of study before death) was the dependent variable. The cohort was analysed separately for patients with and without proteinuria. This was necessary, as we knew from a previous study ${ }^{2}$ that $(a)$ the overall relative mortality was five to 20 times higher in patients with proteinuria than in those without, $(b)$ several variables were associated with increased relative mortality in patients with proteinuria but not in patients without proteinuria, $(c)$ some relevant variables may be estimated only for patients with proteinuria, and $(d)$ development of proteinuria is such a strong risk factor for death that the relevant time scale changes from age or duration of diabetes to duration of proteinuria. In patients without proteinuria death from any cause other than cardiovascular disease, emigration, or development of proteinuria (diabetic or non-diabetic) led to censoring (loss to follow up as a patient without proteinuria). In patients with proteinuria death from any cause other than cardiovascular disease and emigration led to censoring.

In patients without proteinuria the following explanatory variables were included in the analysis: sex, age at diagnosis, current age, year of diagnosis, calendar year during follow up, and duration of diabetes on admission to the Steno Memorial Hospital. In patients with proteinuria the following explanatory variables were also included: year of onset of proteinuria, duration of diabetes at onset of proteinuria, and age at onset of proteinuria. Testing for significant effect of the explanatory independent variables was done by backward selection strategy with exclusion on the basis of a $5 \%$ level.

The logistic failure time model is a so called generalised linear mode ${ }^{16}$ in which the death rates from cardiovascular disease for the population at large-or more precisely the logistic transform of the mortality ratesappear as an offset term (McCullagh and Nelder, p 138). ${ }^{16}$

All continuous explanatory variables were isolated and thereafter introduced as qualitative factors in the systematic component of the mortality. This procedure was adhered to for two reasons. Firstly, there is no reason to assume that the systematic component of the model is a linear function of the continuous covariates. Instead, each level of the separate covariates is assumed to contribute distinct quantities to the systematic component. The estimated parameters (odds ratios) shown in tables II and III seem to justify this view. The parameter specifying the effect of age increases until ages 2645 and thereafter decreases. Secondly, the categorisation of the quantitative variables reduces the problems of aliasing (non-estimability) caused by linear relations among age at diagnosis, year of diagnosis, duration of diabetes, current age, and calendar year during follow up. Intrinsic aliasing due to linear dependence among different terms of the systematic component of the risk of cardiovascular mortality disappears completely when the continuous variables are categorised, whereas extrinsic aliasing still may occur as a result of inexpedient choice of categories combined with unfavourable distribution of the explanatory variables. To ensure that

TABLE II-Predictors of increased cardiovascular relative mortality in patients without proteinuria

\begin{tabular}{|c|c|c|c|c|}
\hline & $-2 \log Q$ & $\begin{array}{l}\text { Degrees } \\
\text { of } \\
\text { freedom }\end{array}$ & $\mathbf{p}$ & $\begin{array}{l}\text { Odds } \\
\text { ratio }\end{array}$ \\
\hline \multicolumn{5}{|c|}{ Significant predictors of cardiovascular mortality } \\
\hline $\operatorname{Sex}(\mathbf{M} / \mathbf{F})$ & $10 \cdot 02$ & 1 & 0.002 & $1 \cdot 0 / 2 \cdot 0$ \\
\hline $\begin{array}{l}\text { Age at diagnosis (years): } \\
\leqslant 5 \\
6-10 \\
11-15 \\
16-20 \\
21-25 \\
26-30\end{array}$ & $15 \cdot 70$ & 5 & 0.008 & $\begin{array}{l}1 \cdot 0 \\
0.7 \\
1.0 \\
0 \cdot 7 \\
0.5 \\
0.3\end{array}$ \\
\hline \multicolumn{5}{|c|}{ Variables with insignificant effect } \\
\hline Age & $4 \cdot 86$ & 4 & 0.30 & \\
\hline Year of diagnosis & $1 \cdot 81$ & 4 & 0.77 & \\
\hline Calendar year during follow up & 1.68 & 4 & 0.79 & \\
\hline Duration of diabetes & 0.05 & 2 & 0.98 & \\
\hline Duration of diabetes on admission & $2 \cdot 25$ & 2 & 0.32 & \\
\hline
\end{tabular}

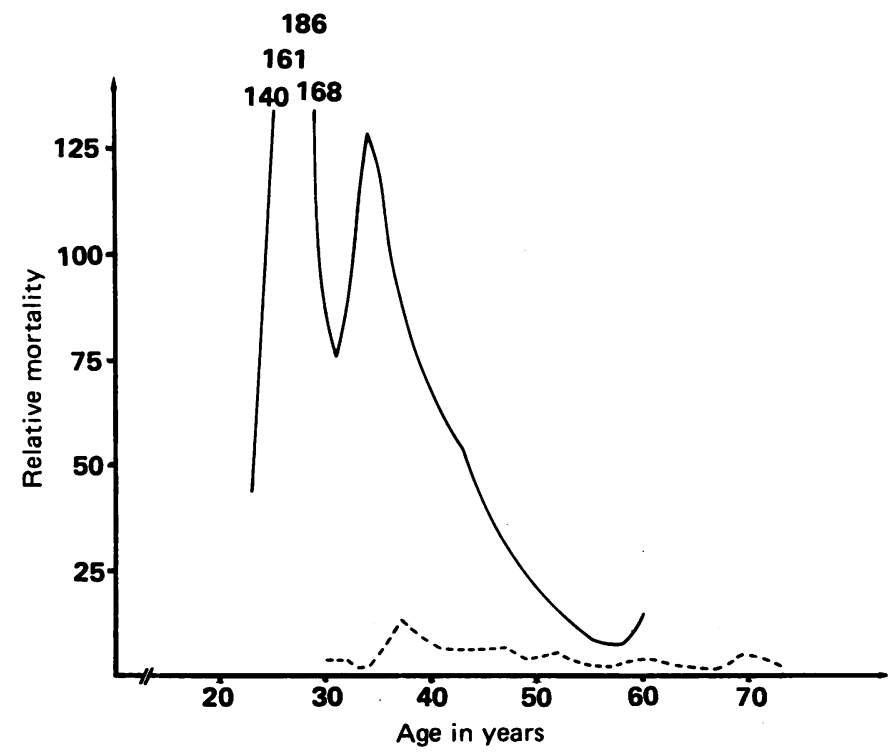

FIG 2-Relative mortality from cardiovascular disease in insulin dependent diabetics with persistent proteinuria (

extrinsic aliasing was not present special care was therefore taken when deciding how to categorise the continuous variables. McCullagh and Nelder (pp 45-53) examined the problems connected with aliasing in more detail. ${ }^{16}$

\section{Results}

The 232 patients for whom data on proteinuria were unobtainable (fig 1) were similar to the study group in their sex distribution, age at onset of diabetes, and calendar year of diagnosis.

Table I shows the basic characteristics of the 722 patients with proteinuria and the 1871 patients who did not develop proteinuria. Patients developing proteinuria were characterised by male preponderance, lower age at diagnosis, and having been diagnosed in the first part of the observation period. The total number of deaths in the study period (1943-83) was 716. Of the 722 patients who had proteinuria on admission or developed it during the study period, 455 died, 109 of cardiovascular disease. Among patients not developing proteinuria 261 died, 101 of cardiovascular disease. The total number of years of observation in the two groups was 4943 years in patients with proteinuria and 40680 years in patients without proteinuria.

Cardiovascular relative mortality in patients with persistent proteinuriaFigure 2 shows the relative mortality from cardiovascular disease in patients with and without proteinuria. Among the 682 patients with proteinuria a total of 109 deaths from cardiovascular disease occurred compared with 2.97 expected. Thus the overall relative cardiovascular disease mortality was $36 \cdot 7$ $(p=0.00002)$. In women the relative mortality was 2.6 times that of men $(p=0.00001)$ (table II). Relative mortality was highest at ages $26-45$ years $(p=0.00004)$ and decreased with increasing calendar year of diagnosis; relative mortality increased with calendar year during follow up from 1943 to 1966 and then remained relatively stable $(p=0.02)$. Patients developing proteinuria before the age of 20 had the highest relative mortality from cardiovascular disease $(p=0.003)$. Neither age at diagnosis, duration of diabetes at onset of proteinuria, duration of proteinuria, calendar year of onset of proteinuria, nor duration of diabetes on admission to the Steno Memorial Hospital significantly influenced relative mortality.

Cardiovascular relative mortality in patients without persistent proteinuriaAmong the 2445 patients without proteinuria on admission (fig 1) a total of 101 deaths from cardiovascular disease occurred compared with 23.3 expected. Thus the overall relative mortality from cardiovasular disease was $4.3(p=0.00001)$. Women had a relative cardiovascular disease mortality twice that of men $(p=0.002)$ (table III), and patients aged $<16$ at diagnosis had the highest relative mortality $(p=0.008)$. Neither duration of diabetes nor current age had any significant effect (table III).

\section{Discussion}

It has previously been shown that the high relative mortality in insulin dependent diabetes can predominantly be ascribed to the development of persistent proteinuria. Our study, comprising a 
representative sample of 2890 Danish insulin dependent diabetics, confirms that this is also true for relative cardiovascular mortality. The most frequent causes of death were myocardial infarction and cardiac insufficiency, but detailed analysis of the causes of death was not undertaken owing to the potential difference in bias between the diabetic and background populations in recording causes of death. The relative mortality from cardiovascular disease was 36.7 in patients with persistent proteinuria compared with only 4.3 in patients without proteinuria. This suggests that the two types of angiopathy seen in insulin dependent diabetes-that is, microangiopathy and macroangiopathy-may be closely related. Other studies have shown that proliferative retinopathy and persistent proteinuria are related, ${ }^{17}{ }^{18}$ whereas the association between microangiopathy and macroangiopathy has only been suggested for non-insulindependent diabetes. ${ }^{78}$

Persistent proteinuria is associated with the development of raised blood pressure and hypercholesterolaemia' ${ }^{19}$ (F ValdorfHansen, unpublished observations). Both factors are known risk factors for cardiovascular disease in non-diabetic subjects. ${ }^{20}{ }^{21}$ Valdorf-Hansen et al (unpublished) have also shown that insulin dependent diabetics with proteinuria have higher serum fibrinogen concentrations and increased platelet adhesiveness in vivo than insulin dependent diabetics of comparable age and duration of diabetes without proteinuria. These studies therefore suggest that patients with persistent proteinuria have a different profile of cardiovascular risk factors from patients without proteinuria. Whether these differences are primary or secondary to the development of persistent proteinuria is, however, unknown, but it is unlikely that these risk factors can explain the 10-fold increase in cardiovascular mortality in diabetics with proteinuria. Genetic factors $^{22}$ or factors affecting the permeability of vessel walls $\mathrm{s}^{23}$ may be equally important.

Patients without proteinuria also showed a significantly increased relative mortality from cardiovascular disease, though much lower than that of patients with proteinuria. This suggests that diabetes by itself is also a significant risk factor for cardiovascular disease, independent of the development of proteinuria, though some of these patients may have had microalbuminuria undetectable by the screening procedures used in our study. Relative mortality was independent of the duration of diabetes, which agrees with findings in non-insulin-dependent disease. ${ }^{24}{ }^{25}$ It is therefore questionable whether the association between diabetes and cardiovascular disease is causal or independent, as discussed by Jarrett. ${ }^{5}$ If diabetes-that is, hyperglycaemia and peripheral hyperinsulinaemia - is the risk factor for cardiovascular disease an effect of duration of the disease should be expected, but this was not the case. Genetic factors associated with the development of insulin dependent diabetes as well as atherosclerosis might therefore explain the observation.

In patients with and without proteinuria a higher relative mortality from cardiovasular disease was found in women than in men. Hence diabetes seems to have different impact as a risk factor in the two sexes. This agrees with studies on non-insulin-dependent diabetes by Barrett-Connor and Wingard ${ }^{26}$ and the Framingham study ${ }^{27}$ though other groups have reached opposite conclusions. ${ }^{28} \mathrm{~A}$ similar trend has been found in insulin dependent diabetics but, as discussed by Jarrett, ${ }^{28}$ previous studies were based on small groups of patients. In the non-diabetic population cardiovascular morbidity as well as mortality were higher in men, certainly up to age $60 .{ }^{29}$ In our study men and women had identical absolute mortality rates, whether in the groups with or without proteinuria. Thus women with insulin dependent diabetes appear not to have the usual relative protection from cardiovascular disease.

Our findings show an association between proteinuria and cardiovascular disease. A significant increase in cardiovascular disease was also found in patients without proteinuria. The reason for this remains unknown, though clustering and interaction of cardiovascular risk factors-for example, smoking, hypertension, and hypercholesterolaemia in diabetic patients - have been suggested..$^{30}$ We were unable to evaluate the impact of these well known risk factors, as data on blood pressure, smoking habits, and blood lipid concentrations were unobtainable in the reference population. Further prospective studies are needed to evaluate the role of standard cardiovascular risk factors in insulin dependent diabetes.

In conclusion, our study shows a strong association between diabetic microangiopathy and macroangiopathy. The increased mortality from cardiovascular disease was found predominantly in patients who had developed persistent proteinuria. A significantly increased mortality, however, was found even in patients without proteinuria, suggesting that diabetes by itself either directly or more likely indirectly confers a risk of developing cardiovascular disease. Both in patients with and in patients without proteinuria the relative mortality was higher in women than in men.

This study was supported by grants from the Danish Diabetes Association (Diabetesforeningen) and Nordisk Insulinlaboratorium. We are grateful for the help of Mrs V Rosenkrantz, of the National Board of Health, department $\mathrm{B}$, in obtaining the death certificates and to $\mathrm{Mr}$ Knud Juhl, Danish Institute of Clinical Epidemiology, for providing the cause specific mortality rates. We also acknowledge the general practitioners and departments of internal medicine for information about the patients and Dr Allan KofoedEnevoldsen, who collected data on the development of proteinuria.

\section{References}

1 Green A, Borch-Johnsen K, Andersen PK, et al. Relative mortality of type 1 (insulin-dependent) diabetes in Denmark 1933 to 1981. Diabetologia 1985;28:339-42.

2 Borch-Johnsen K, Andersen PK, Deckert T. The effect of proteinuria on relative mortality in type 1 (insulin-dependent) diabetes mellitus. Diabetologia 1985;28:590-6.

Jarrett RJ, Keen H, Chakrabarti R. Diabetes, hyperglycaemia and arterial disease. In: Keen H, Jarrett RJ, eds. Complications of diabetes. London: Edward Arnold, 1982:179-204.

Ganda Diabetic. Diabetes 1980;29. 931-42.

5 Jarrett RJ. Type 2 (non-insulin-dependent) diabetes mellitus and coronary heart diseasechicken, egg or neither? Diabetologia 1984;26:99-102.

6 Goodman G. Mortality factors in diabetes. J Occup Med 1975;17:716-21.

7 Mogensen CE. Microalbuminuria predicts clinical proteinuria and early mortality in maturity onset diabetes. N Engl Y Med 1984;6:356-60.

8 Jarrett RJ, Viberti GC, Argyropoulos A, HIII RD, Mahmud U, Murrel TJ. Microalbuminuria predicts mortality in non-insulin-dependent diabetes. Diabetic Medicine 1984;1:17-9.

9 Kofoed-Enevoldsen A, Borch-Johnsen K, Kreiner S, Deckert T. Declining incidence of proteinuria in type 1 (insulin-dependent) diabetes mellitus. Diabetes (in press)

10 Christau B, Kroman H, Christy M, Ortved Andersen O, Nerup J. Incidence of insulin-dependent diabetes mellitus (0-29 years at onset) in Denmark. Acta Med Scand 1979;624(suppl):54-60.

11 Astrup P, Brechner Mortensen K, Faber M. Clinical laboratory techniques. Copenhagen: August Bang, 1959.

12 Hemmingsen L, Skaarup P. Diagnostic value of a test-strip in detecting increased urinary excretion of albumin, IgG and beta-2-microglobulin in patients with suspected proteinuria. Scand F Clin Lab Invest 1981;41:785-9.

13 Skandinavisk Nomenklatur af 1926. Dedsaarsagerne i Kongeriget Danmark iaaret 1946. Copenhagen: Fr Bagges Kgl Hofbogtrykkeri, 1947.

14 Kalbfleisch JO, Prentice RW. The statistical analysis of failure time data. New York: Wiley, 1980. 15 Borch-Johnsen K, Kreiner S, Deckert T. Mortality of type 1 (insulin-dependent) diabetes mellitus in Denmark: a study of relative mortality in 2930 Danish type 1 diabetic patients diagnosed from 1933 to 1972. Diabetologia 1986;29:767-72.

6 McCullagh P, Nelder JA. Generalized linear models. London, New York: Chapman and Hall, 1983.

7 Klein R, Klein BEK, Moss SE, Davis MD, DeMets DL. The Wisconsin epidemiology study of diabetic retinopathy: proteinuria and retinopathy in a population of diabetic persons diagnosed pret prior to 30 years of age. In: Friedman EA, L'Esperat York: Grune and Stratton, 1986:245-64.

18 Kofoed-Enevoldsen A, Jensen T, Borch-Johnsen K, Deckert T. Development of clinical nephropathy in type 1 (insulin-dependent) diabetic patients implies a high risk for proliferative nephropathy in type 1 (insulin-dependent) diabetic patients implies a high risk for proliferative retinopathy; 22nd

9 Parving H-H, Andersen AR, Smidt UM, Oxenbøll B, Edsberg B, Sandahl Christiansen J. Diabetic nephropathy and arterial hypertension. Diabetologia 1983;24:10-2.

20 Christlieb AR. The hypertension of diabetes. Diabetes Care 1982;5:50-8.

21 Lipid Research Clinics Program. The lipid research clinics. Coronary primary prevention trial results. JAMA 1984;251:351-74.

22 Barnett AH, Pyke DA. The genetics of diabetic complications. Clin Endocrinol Metab $1986 ; 15: 715-26$

23 Feldt-Rasmussen. B. Increased transcapillary escape rate of albumin in type 1 (insulin-dependent) diabetic patients with microalbuminuria. Diabetologia 1986;29:282-6.

4 Panzram G, Ruhmann B. Prognose des diabetes mellitus nach frühdiagnose durch glucosuriescreening. Schweiz Med Wochenschr 1978;108:221-5.

25 Waller BF, Palumbo PJ, Lie JT, Roberts WC. Status of the coronary arteries at necropsy in diabetes mellitus with onset after age 30 years: analysis of 229 diabetic patients with and without clinical evidence of coronary heart disease and comparison to 183 control subjects. Am $\mathcal{J}$ Med 1980;69:498-506.

26 Barrett-Connor $\mathrm{E}, \mathrm{W}$ ingard $\mathrm{D}$. Sex differential in ischemic heart disease in diabetics: a prospective population-based study. Am $\mathcal{F}$ Epidemiol 1983;118:489-96.

27 Kannel WB, McGee DL. Diabetes and cardiovascular disease. The Framingham study. JAMA 1979;241:2035-8.

28 Jarrett RJ, ed. The epidemiology of coronary heart disease and related factors in the context of diabetes mellitus and impaired glucose tolerance. In: Diabetes and heart disease. Amsterdam: Elsevier, 1984:1-23.

29 Schroll M, Larsen S. A ten year prospective study, 1964-1974, of cardiovascular risk factors in men and women from the Glostrup population born 1914. Dan Med Bull 1981;28:236-51.

30 Barrett-Connor E, Orchard T. Diabetes and heart disease. In: Harris MI, Hammen RF, eds. Diabetes in America, ser XVI. Washington: National Institute of Health, 1985:1-41. (NIH publication 85-1468.)

(Accepted 23 April 1987) 